\title{
Presentation of Hospital Outcomes and Different Treatment Methods of Patients with Budd-Chiari Syndrome: A Report from Two Tertiary Hospitals in Iran
}

\author{
Mahmoud Ebrahimi ${ }^{a, b}$ Mohammad Hadi Modaghegh ${ }^{c}$ Abbas Esmaeilzadeh $^{d}$ \\ ${ }^{a}$ Department of Cardiology, ${ }^{b}$ Cardiovascular Research Center, ${ }^{C}$ Department of Surgery, and ${ }^{\mathrm{d}}$ Department of \\ Internal Medicine, Mashhad University of Medical Sciences (MUMS), Mashhad, Iran
}

\section{Key Words}

Budd-Chiari syndrome $\cdot$ Etiology $\cdot$ Treatment methods

\begin{abstract}
Objective: The aim of this study was to report common presentations of Budd-Chiari syndrome (BCS) and the early outcome of different treatment methods in two tertiary hospitals in Iran. Subjects and Methods: This case series study was performed on 21 patients (mean age: $42 \pm 13.09$ years; 11 male, $52.4 \%$, and 10 female, $47.6 \%$ ) admitted for treatment of BCS in two tertiary referral centers in Mashhad, Iran, between 2002 and 2008. All required data of signs, underlying etiology, treatment methods and in-hospital mortality were gathered from patients' medical records. Results: Angiographic and sonographic findings showed that the most frequent isolated location of obstruction was the inferior vena cava $(n=12,57.1 \%)$. No distinct underlying disease was found in $6(28.6 \%)$ patients. Eleven (52.4\%) patients had web obstruction and 4 patients had other related underlying diseases. Treatment modalities consisted of medical follow-up in $12(57.1 \%)$, angioplasty in $6(28.6 \%)$, and surgery in $3(14.3 \%)$ patients. Medical follow-up of 3 patients, 1 with angioplasty and 2 who had undergone surgery, disclosed that they had died before discharge from hospital. Conclusion: Higher age at diagnosis may reflect late diagnosis at an advanced stage
\end{abstract}

of disease. We suggest that the early symptoms of this disease should be taken into account more seriously in differential diagnosis. Balloon angioplasty seems to be a more efficient method for treatment of BCS.

Copyright $\odot 2011$ S. Karger AG, Basel

\section{Introduction}

Budd-Chiari syndrome (BCS) is characterized by a group of uncommon varied disorders defined by hepatic venous outflow obstruction at the level of the hepatic venules, large hepatic veins, inferior vena cava, or right atrium [1]. This syndrome occurs in $1 / 100,000$ of the general population [2]. There is some evidence that BCS is a result of acquired predisposing factor(s) affecting a susceptible individual with one or more underlying thrombophilic conditions [3]. The presentations of BCS are as follows: hematological disorders, inherited thrombotic diathesis, pregnancy and postpartum, web obstruction (as a presentation), use of oral contraceptives, chronic infections, chronic inflammatory diseases (as in Behçet's disease), tumors and miscellaneous (trauma) and idiopathic (or unidentified) disorders $[2,4,5]$. An underlying disorder can be identified in over $80 \%$ of patients with BCS $[6,7]$.

\section{KARGER}

Fax +4161306 1234

E-Mail karger@karger.ch

www.karger.com (c) $2011 \mathrm{~S}$. Karger AG, Basel

$1011-7571 / 11 / 0203-0287 \$ 38.00 / 0$

Accessible online at:

www.karger.com/mpp
Dr. Mahmoud Ebrahimi

Department of Interventional Cardiology, Cardiovascular Research Center Imam Reza Hospital, Mashhad University of Medical Sciences (MUMS) Mashhad (Iran)

Tel. +98 9151118 714, Fax +98 511768 4522, E-Mail ebrahimi_cardiology@yahoo.com 
Myeloproliferative disorders are the leading cause of BCS in Western countries, occurring in $20-53 \%$ of BCS patients $[2,8]$. Various types of medical therapy, such as transcatheter interventions, different kinds of open surgery, and liver transplantation are considered for patients with BCS $[5,9]$. Based on our current experience, BCS will be one of the important health problems in Iran. Due to lack of sufficient data regarding a general overview of presentations of BCS, different treatment methods and in-hospital outcomes for patients with BCS in Iran, a retrospective analysis of this syndrome was conducted for two tertiary hospitals in Iran.

\section{Subjects and Methods}

This study was carried out on all patients admitted for treatment of BCS in two tertiary referral centers, Imam Reza and Ghaem Hospitals, in Mashhad, Iran, between 2002 and 2008. The following data were obtained from the patients' medical records: signs (ascites, esophageal varices, hepatomegaly, edema, icterus, abdominal pain, splenomegaly and encephalopathy); underlying etiology and presentations (hematological disorders, inherited thrombotic diathesis, pregnancy and postpartum, membranous webs, use of oral contraceptives, chronic infections, chronic inflammatory diseases, tumors) and idiopathic.

All the patients' records showed a documented diagnosis of BCS based on clinical features, biochemical tests, sonography and angiography.

Treatment methods included medical therapy (efforts to control the further development of ascites, the use of anticoagulation therapy to prevent further extension of the venous thrombosis, and treatment of detectable underlying causes), intravascular interventions and different kinds of open surgery that were gathered from the medical records of all patients. The data were analyzed using Mini-Tab (release 13, Minitab Inc., 2000, USA), with descriptive statistics (mean and standard deviation) being determined for all variables.

\section{Results}

A total of 21 patients, 11 (52.4\%) males and $10(47.6 \%)$ females, were studied; mean age was $42 \pm 13.09$ years (range: 28-69) (table 1). The age distribution was $<30$ years: $\mathrm{n}=4 ; 30-40$ years: $\mathrm{n}=6 ; 40-50$ years: $\mathrm{n}=9$, and $>50$ years: $\mathrm{n}=2$.

Nineteen $(90.5 \%)$ patients presented with ascites, varicose vein: $\mathrm{n}=6$ (28.6\%), hepatomegaly: $\mathrm{n}=8(38.1 \%)$, edema: $\mathrm{n}=14(66.6 \%)$, abdominal pain: $\mathrm{n}=5(28.85 \%)$ and encephalopathy: $\mathrm{n}=12$ (57.1\%). Obviously, some patients had more than one presenting symptom. Imaging (angiography and sonography) findings showed that the
Table 1. Age and gender characteristics of the sample population, site of obstruction and causes of BCS

\begin{tabular}{lc}
\hline $\begin{array}{l}\text { Age, years } \\
\text { Gender }\end{array}$ & $42 \pm 13.09$ \\
$\quad$ Male & $11(52.4 \%)$ \\
$\quad$ Female & $10(47.6 \%)$ \\
Site of obstruction & \\
$\quad$ Isolated IVC & $12(57.1 \%)$ \\
$\quad$ Hepatic vein & $6(28.6 \%)$ \\
IVC and hepatic & $3(14.3 \%)$ \\
Presentation/underlying disease of BCS & \\
Web & $11(52.4 \%)$ \\
Unidentified underlying disease & $6(28.6 \%)$ \\
Behçet's disease & $2(9.5 \%)$ \\
Hepatitis C & $1(4.8 \%)$ \\
Leukemia & $1(4.8 \%)$
\end{tabular}

IVC $=$ Inferior vena cava

most frequently identified location of obstruction was the inferior vena cava, which occurred in 12 (57.1\%) patients (table 1).

Our findings showed that 11 (52.4\%) of the BCS patients had web obstruction. However, 6 (28.6\%) of the patients were categorized with unidentified underlying disease or idiopathy. The underlying disease of the remaining patients was as follows: Behçet's disease: $\mathrm{n}=2(9.5 \%)$, hepatitis C: $\mathrm{n}=1$ (4.8\%), leukemia: $\mathrm{n}=1$ (4.8\%) (table 1). Behçet's disease was also found in 1 patient who had a web obstruction as the major cause of BCS.

The chosen methods of treatment were medical therapy: $\mathrm{n}=12(57.1 \%)$, angioplasty: $\mathrm{n}=6(28.6 \%)$, and surgery: $\mathrm{n}=3$ (14.3\%). In 9 patients with web obstruction as a cause of BCS, balloon angioplasty was successfully performed in 6 (28.6\%) and 3 (14.3\%); others were referred for surgery because of thickening of the web lesions.

Three patients with encephalopathy upon admission died before discharge from the hospital. One who had been admitted with acute liver failure and encephalopathy died 5 days after successful angioplasty. In the surgical group, 2 with some degree of encephalopathy and liver failure upon admission succumbed after surgery.

\section{Discussion}

In this study, the mean age of patients diagnosed with BCS was 10 years older than that reported in India and Turkey $[4,10]$, which might be due to different causative 
factors or later diagnosis in Iran. The most frequent presenting sign for Iranian patients with BCS was ascites, consistent with an Indian report [10], indicating that BCS should be suspected in patients with abrupt onset of ascites and painful hepatomegaly and also massive ascites with liver function relatively preserved [11].

Isolated inferior vena cava obstruction was the commonest disease in our study, consistent with a previous report [4]. However, in more recent reports a combination of inferior vena cava and hepatic vein obstruction was the commonest type [3], which in our study was the second type. Longer duration of illness has been shown to be associated with inferior vena cava obstruction [3, 12] and indicates a late diagnosis of BCS in Iran.

According to our experience, web obstructions are the most common presenting sign of BCS in Iranian patients, consistent with other reports from the East $[4,13,14]$, but not in the Western hemisphere, where myeloproliferative disorders are the most prevalent underlying disease in BCS patients $[2,8,15]$. It is often thought that membranous lesions are congenital in origin; however, the mechanisms that result in their formation are not clear despite numerous epidemiological studies [16]. The interesting point in this regard is that the higher number $(n=5)$ of older patients with web-based BCS is not consistent with the congenital formation of web obstructions. Until the present time, there are rare reports of BCS in children. Some investigators believe that formation of membranous occlusions can occur during adulthood [17].

About $30 \%$ of Iranian patients with BCS remained unidentified, consistent with another report from Turkey [4]. Other researchers have reported an exact diagnosis of BCS for about $80 \%[6,7]$ of patients, which clarifies the lower rate of exact diagnosis in Iran that might be due to medical and technical problems.

Vasculitis is a major component of Behçet's disease. Hepatic vein vasculitis, which occurs in patients with Behçet's disease, may cause BCS [18], which again, is not uncommon in Behçet's disease patients [19]. In patients with Behçet's disease, BCS is often associated with inferior vena cava as well as hepatic venous thrombosis [19], exactly the finding in our study: 2 of the patients with BCS in Iran had Behçet's disease.

Comorbidity of hepatitis C and BCS was observed in 1 patient. We do not believe that hepatitis $\mathrm{C}$ can be a causative factor for the development of BCS, a view that may be corroborated by an investigation of the causes of BCS by Mesa [20], who also reported a co-infection of hepatitis $\mathrm{C}$ in a patient with BCS, but did not conclude that hepatitis C was a causative factor of BCS [21].

Etiology and Treatment of Budd-Chiari Syndrome
Interventional therapy or radical resection of web lesions is now an accepted method [6]. Percutaneous transluminal angioplasty is another safe and useful method for the management of BCS due to membranous obstruction of the hepatic portion of the inferior vena cava or the hepatic veins [22]. In our study, 6 patients with BCS caused by web obstruction were successfully treated with balloon angioplasty. Perhaps new interventional transcatheter methods that are minimally invasive will replace surgical techniques.

If BCS is not treated punctually and properly, the outcome may be fatal [23]. Seven of 21 (33\%) patients died in hospital before discharge. The observed 33\% death rate of our patients in the hospital before discharge is a very high rate of mortality. However, others have reported higher survival rates for BCS: $87 \%$ at 1 year and $82 \%$ at 2 years [24] and survival rates at 1,3 , and 5 years after shunting of 83,78 , and $75 \%$, respectively [25].

Inclusive imaging evaluations, in combination with pathologic analyses and clinical testing, are necessary for determining the severity of disease, stratifying risk, selecting the suitable therapy, and impartially assessing the response [23]. Our results demonstrated that the current status of the patients with BCS in Iran is critical. Urgent systematic reactions for proper screening and precise follow-up of patients with BCS are required in Iran. It seems that special attention should be paid in this regard by physicians and medical associations.

In comparison with Western countries, Iranian patients with BCS had more web obstructions than hematologic disorders, as shown in the study by Darwish $\mathrm{Mu}$ rad et al. [24] where myeloproliferative disorder was a common cause of BCS. A probable explanation for the difference is that we did not measure JAK2 V617F mutation as an indicator of myeloproliferative disorder, as was done by Darwish Murad et al. [24].

\section{Conclusion}

Higher age at diagnosis may reflect late diagnosis in an advanced stage of disease. We suggest that the early symptoms of this disease should be taken into account more seriously in differential diagnosis. Balloon angioplasty seems to be a more efficient method for treatment of BCS. 


\section{References}

1 Menon KV, Shah V, Kamath PS: The BuddChiari syndrome. N Engl J Med 2004;350: 578-585.

-2 Aydinli M, Bayraktar Y: Budd-Chiari syndrome: etiology, pathogenesis and diagnosis. World J Gastroenterol 2007;13:2693-2696.

3 Eapen CE, Mammen T, Moses V, Shyamkumar NK: Changing profile of Budd-Chiari syndrome in India. Indian J Gastroenterol 2007;26:77-81.

-4 Uskudar O, Akdogan M, Sasmaz N, Yilmaz S, Tola M, Sahin B: Etiology and portal vein thrombosis in Budd-Chiari syndrome. World J Gastroenterol 2008;14:2858-2862.

5 Zhang XM, Li QL: Etiology, treatment, and classification of Budd-Chiari syndrome. Chin Med J 2007;2:159-161.

$\checkmark 6$ Dilawari JB, Bambery P, Chawla Y, Kaur U, Bhusnurmath SR, Malhotra HS, Sood GK, Mitra SK, Khanna SK, Walia BS: Hepatic outflow obstruction (Budd-Chiari syndrome): experience with 177 patients and a review of the literature. Medicine 1994;73:21.

7 Case records of the Massachusetts General Hospital. Weekly clinicopathological exercises. Case 51-1987. Progressive abdominal distention in a 51-year-old woman with polycythemia vera. N Engl J Med 1987;317:1587.

$>8$ Denninger $\mathrm{MH}$, Chait Y, Casadevall N, Hillaire S, Guillin MC, Bezeaud A, Erlinger S, Briere J, Valla D: Cause of portal or hepatic venous thrombosis in adults: the role of multiple concurrent factors. Hepatology 2000; 31:587-591.

$>9$ Klein AS: Management of Budd-Chiari syndrome. Liver Transpl 2006;12(11 suppl 2): S23-S28.
10 De BK, De KK, Sen S, Biswas PK, Das TK, Das S, Hazra B: Etiology based prevalence of Budd-Chiari syndrome in eastern India. J Assoc Physicians India 2000;48:800-803.

11 Ohta M, Hashizume M, Tomikawa M, Ueno K, Tanoue K, Sugimachi K: Analysis of hepatic vein waveform by Doppler ultrasonography in 100 patients with portal hypertension. Am J Gastroenterol 1994;89:170-175.

12 Iwai M, Kitagawa Y, Nakajima T, Takeda M, Okanoue T, Nakajima T, Ogasawara T, Suyama Y, Miyoshi M, Kashima K: Clinical features, image analysis, and laparoscopic and histological liver findings in BuddChiari syndrome. Hepatogastroenterology 1998;45:2359-2368.

13 Shrestha SM, Okuda K, Uchida T, Maharjan KG, Shrestha S, Joshi BL, Larsson S, Vaidya Y: Endemicity and clinical picture of liver disease due to obstruction of the hepatic portion of the inferior vena cava in Nepal. J Gastroenterol Hepatol 1996;11:170-179.

14 Okuda H, Yamagata H, Obata H, Iwata H, Sasaki R, Imai F, Okudaira M, Ohbu M, Okuda K: Epidemiological and clinical features of Budd-Chiari syndrome in Japan. J Hepatol 1995;22:1-9.

15 Hirshberg B, Shouval D, Fibach E, Friedman G, Ben-Yehuda D: Flow cytometric analysis of autonomous growth of erythroid precursors in liquid culture detects occult polycythemia vera in the Budd-Chiari syndrome. J Hepatol 2000;32:574-578.

16 Wang ZG: Budd-Chiari syndrome. Curr Probl Surg 1996;33:83-211.

17 Li XQ, Duan PF, Qian AM, Sang HF: Reoperation for postoperation recurrence in Budd-Chiari syndrome patients undergoing radical resection. Chin J Gen Surg (Chin) 2005;20:274-275.
18 Bayraktar Y, Balkanci F, Kansu E, Dundar S, Uzunalimoglu B, Kayhan B, Telatar H, Gurakar A, Van Thiel DH: Cavernous transformation of the portal vein: a common manifestation of Behçet's disease. Am J Gastroenterol 1995;90:1476-1479.

19 Ben Ghorbel I, Ennaifer R, Lamloum M, Khanfir M, Miled M, Houman MH: BuddChiari syndrome associated with Behçet's disease. Gastroenterol Clin Biol 2008;32: 316-320.

20 Mesa RA: How I treat symptomatic splenomegaly in patients with myelofibrosis. Blood 2009;113:5394-5400.

21 Shrestha SM: Liver cirrhosis and hepatocellular carcinoma in hepatic vena cava disease, a liver disease caused by obstruction of inferior vena cava. Hepatol Int 2009;3:392-402.

-22 Sparano J, Chang J, Trasi S, Bonanno C. Treatment of the Budd-Chiari syndrome with percutaneous transluminal angioplasty: case report and review of the literature. Am J Med 1987;82:821-828.

23 Cura M, Haskal Z, Lopera J: Diagnostic and interventional radiology for Budd-Chiari syndrome. Radiographics 2009;29:669-681.

24 Darwish Murad S, Plessier A, HernandezGuerra M, Fabris F, Eapen CE, Bahr MJ, Trebicka J, Morard I, Lasser L, Heller J, Hadengue A, Langlet P, Miranda H, Primignani M, Elias E, Leebeek FW, Rosendaal FR, Garcia-Pagan JC, Valla DC, Janssen HL; EN-Vie (European Network for Vascular Disorders of the Liver): Etiology, management, and outcome of the Budd-Chiari syndrome. Ann Intern Med 2009;151:167-75.

25 Slakey DP, Klein AS, Venbrux AC, Cameron JL: Budd-Chiari syndrome: current management options. Ann Surg 2001;233:522-527. 